\title{
The Relationship of Hepatits B Core Antibody Positivity with Demographic and Laboratory Parameters in Hemodialysis Patients
}

\author{
(- Ilter Bozaci, ๑ Selma Tosun* \\ University of Health Sciences Turkey, Bozyaka Training and Research Hospital, Clinic of Nephrology, Izmir, Turkey \\ *University of Health Sciences Turkey, Bozyaka Training and Research Hospital, Clinic of Clinical Microbiology and Infectious Diseases, \\ Izmir, Turkey
}

\section{Abstract}

\begin{abstract}
Aim: The presence of hepatitis B core antibody ( $\mathrm{HBCAb})$ is an indication of exposure to hepatitis $B$ virus infection. We aimed to investigate the rates of positive $\mathrm{HBCAb}$ and its' association with demographical and laboratory parameters among patients undergoing hemodialysis.
\end{abstract}

Methods: Patients were divided into two groups as HBCAb positive and HBCAb negative. This study was conducted at a training and research hospital over 3 months period between October and December 2020. Demographical data and laboratory results were recruited from most recent medical records.

Results: A sum of 237 patients on hemodialysis were enrolled in the study. Fifty nine patients (25\%) were HBcAb positive and 178 patients (75\%) were HBcAb negative. Statistically significant difference was found between groups in terms of anti-HBs positivity (96.6\% vs 79.2\%; $p=0.002$ ), diabetes mellitus (DM) prevalence ( $32 \%$ vs $19 \% ; p=0.036)$ and white blood cell count (WBC) levels (7.7 $\pm 2.5 \times 10^{3} /$ $\mu \mathrm{L}$ vs $\left.7.1 \pm 2.1 \times 10^{3} / \mu \mathrm{L} ; \mathrm{p}=0.044\right)$. In linear regression analysis (variables: age, HBsAb, WBC and DM) HBcAb was found independently associated with age (t: 3.139; $p=0.002), \operatorname{HBsAb}(t: 3.998 ; p<0.001), W B C(t: 2.166 ; p=0.031)$ and DM (t: 2.749; $p=0.006)$.

Conclusion: We found high rates of positive HBcAb. Positive HBCAb should be taken into account in immune-compromised patients such as dialysis patients.

Keywords: Hepatitis B virus, hepatitis B antibodies, hepatitis B core antigens, hemodialysis

\section{Introduction}

Patients on hemodialysis are under increased risk for hepatitis B virus (HBV) infection $(1,2)$. The incidence of hepatitis B infection was about $0.12 \%$ in patients undergoing dialysis in the United States in 2002 (3). The incidence of HBV infection in dialysis differ worldwide according to the endemicity at in that region (4). The presence of hepatitis B core antibody (HBCAb) is an indication of exposure to HBV infection. In patients with $\mathrm{HBCAb}$ positive, when HBsAg is negative, HBV-DNA testing is not performed because these patients are not considered to be infectious. In case of receiving immune suppressive treatment, immune-suppressed patients such as hemodialysis patients with positive $H B c A b$, must receive prophylactic antiviral therapy against hepatitis $B$ reactivation. Despite high antibody titers, reactivation of HBV infection has been shown in the literature after immunosuppressive therapy in $\mathrm{HBCAb}$ positive patients (5). Another important issue related to positive $H B C A b$ is occult hepatitis $B$ infection (OBI) which occurs as the result of mutations at the genes those encode surface antigen of HBV (6). Two subgroups of OBI according to the presence of serological markers had been described. If only HBV-DNA is positive whereas both HBsAg and $H B c A b$ are negative, this situation is called seronegative $\mathrm{OBI}$. On the other hand, if HBV-DNA is positive with the seropositivity of either $\mathrm{HBCAb}$ and HBsAg together or with the seropositivity of $H B C A b$ alone, this situation is

Yazışma Adresi/Address for Correspondence: Ilter Bozaci, University of Health Sciences Turkey,

Bozyaka Training and Research Hospital, Clinic of Nephrology, Izmir, Turkey

Phone: +90 2322405050 E-mail: ilterbozaci@gmail.com ORCID: orcid.org/0000-0001-7535-9403

Received: 04.01.2021 Accepted: 13.02.2021

Copyright 2021 by The Medical Bulletin of istanbul Haseki Training and Research Hospital The Medical Bulletin of Haseki published by Galenos Yayınevi. 
called seropositive OBI. In both types, common laboratory finding is the positivity of HBV-DNA (7). In the literature, it was shown that the incidence of seronegative $O B I$ is about $20 \%$ of all OBI cases (8). After the routine clinical use of the HBsAg test, there has been a serious decrease in HBV infection rates. However, testing for HBsAg solely is not sufficient to detect $\mathrm{OBI}$ cases. The clinical significance of $\mathrm{OBI}$ is based on its possible clinical consequences. The undetected and untreated $\mathrm{OBI}$ may result with hepatocellular complications including carcinoma and cirrhosis (9). In addition, if $\mathrm{OBI}$ cases are not properly isolated, HBV infection can be transmitted in dialysis units.

In the present study, we investigated the rates of positive HBCAb and its' association with demographical data and laboratory parameters among patients undergoing hemodialysis in our cohort.

\section{Methods}

\section{Study Design}

The study was approved by institutional ethics committee of Izmir Bozyaka Training and Research Hospital at the (number; 4, date: 28.10.2020). This study was conducted at a training and research hospital and its satellite dialysis units over 3 months period between October and December 2020. The study included hemodialysis patients who were older than 18 years old. All patients were enrolled in the study after providing written informed consent. Patients with overt HBV infection with positive HBsAg and HBV-DNA were excluded. The patients included in the study were divided into two groups according to the presence of $\lg G$ type HBcAb positivity.

\section{Laboratory Assessment}

The plasma samples were obtained during monthly periodic visits of hemodialysis patients enrolled in the study. The serological markers of HBV, hepatitis $C$ virus $(\mathrm{HCV})$ and human immunodeficiency virus (HIV) were determined via ELISA (Access and Bio Rad, BeckmanCoulter, California, USA) kits. HBV-DNA and HCV-RNA were measured by polymerase chain reaction (PCR) technique with the manufacturers Artus GmbH HBV RG PCR kit, Hamburg, Germany and Cobas Amplicor HCV Monitor test, version 2.0 kit, Roche Diagnostic Systems, California, USA, respectively. The information about the vaccination and the history of blood transfusion of each patients was obtained from medical records. Arrangement of the normal limits of alanine and aspartate aminotransferases were done according to the data in the literature (10). Demographical data such as age and gender, laboratory data such as complete blood count results, albumin levels, haemoglobin A1c levels [in patients with diabetes mellitus
(DM)], kt/ $\mathrm{V}$ and urea reduction ratio (URR) results were obtained from most recent medical records.

\section{Statistical Analysis}

Categorical variables those were compared using the chi-square test and Fischer's Exact test, were reported as number and percentages. Besides, continuous parametric variables those were compared using Student's t-test, were reported as means \pm standard deviation. Mann-Whitney $U$ test was used to compare parameters not showing normal distribution such as aspartate transaminase (AST), alanine aminotransferase (ALT), time of last vaccination and antibody titers. Linear regression analysis was made for $\mathrm{HBCAb}$. In linear regression analysis of $\mathrm{HBCAb}$ variables were age, HBsAb, WBC and DM. The comparison was made using the Enter method. SPSS18.0 (Chicago, IL USA) was used in performing statistical analysis. The threshold value in terms of statistical significance was $p<0.05$.

\section{Results}

A sum of 237 hemodialysis patients were enrolled in the study. Fifty-nine patients (25\%) were HBcAb positive and 178 patients (75\%) were HBcAb negative. Twenty patients (34\%) in HBcAb positive patients and 76 patients $(43 \%)$ in $\mathrm{HBCAb}$ negative patients were female. There was no statistically significant difference between $\mathrm{HBCAb}$ positive and $\mathrm{HBCAb}$ negative patients in terms of gender [34/66 female (F)/male (M) (\%) vs 43/57 F/M $(\%) ; p=0.23]$. There was statistically significant difference between $\mathrm{HBCAb}$ positive and $\mathrm{HBCAb}$ negative patients in terms of age ( $64 \pm 11$ vs $60 \pm 15 ; p=0.018)$, respectively. There were 2 patients $(0.8 \%)$ with isolated positive $H B C A b$. $\mathrm{HBV}$-DNA results were negative in HBcAb positive patients including either isolated $\mathrm{HBCAb}$ or in patients with positive $\mathrm{HBcAb}$ and/or HBsAb. Demographical and laboratory results of $H B C A b$ positive and $H B C A b$ negative patients are presented in Table 1. The distribution of patients in $\mathrm{HBCAb}$ positive and $\mathrm{HBCAb}$ negative patients in terms of gender is presented in Figure 1.

$\mathrm{HBsAb}$ was positive in 57 of 59 patients in $\mathrm{HBcAb}$ positive patients; 141 of 178 patients in HBcAb negative patients and there was statistically significant difference between $\mathrm{HBCAb}$ positive and $\mathrm{HBCAb}$ negative patients in terms of HBsAb positivity (96.6\% vs $79.2 \%$; $p=0.002$ ), respectively. In terms of $\mathrm{HBsAb}$ titers, there was no significant difference between $\mathrm{HBCAb}$ positive and $\mathrm{HBCAb}$ negative patients [196.6 (469.1) $\mathrm{mlU} / \mathrm{mL}$ vs 136.2 (425.6) $\mathrm{mlU} / \mathrm{mL} ; \quad p=0.111]$. There was statistically significant difference between $\mathrm{HBCAb}$ positive and $\mathrm{HBCAb}$ negative patients in terms of the mean time of last vaccination [12 (30) months vs 5 (17) months; $p=0.012$ ], respectively.

Type-2 DM was in 19 of 59 patients in HBcAb positive patients and 34 of 178 patients in $\mathrm{HBCAb}$ negative patients 
and there was statistically significant difference between groups ( $32 \%$ vs $19 \% ; p=0.036$ ), respectively. The history of blood transfusion was in 11 of 59 patients in $\mathrm{HBCAb}$ positive patients and 27 of 178 patients in $\mathrm{HBCAb}$ negative patients and there was no statistically significant difference between groups ( $19 \%$ vs $15 \%$; $p=0.528$ ). In terms of dialysis sufficiency, there was no statistically significant difference between $\mathrm{HBCAb}$ positive and $\mathrm{HBcAb}$ negative patients in terms of $\mathrm{kt} / \mathrm{V}(1.5 \pm 0.3$ vs $1.6 \pm 0.4 ; p=0.104)$ and URR ( $71 \pm 7 \%$ vs $72 \pm 8 \% ; p=0.490)$, respectively.

In terms of laboratory parameters that we evaluated between $H B C A b$ positive and $H B c A b$ negative patients, although the results were close, there was statistically significant difference in terms of WBC levels $(7.7 \pm 2.5$ $\mathrm{x} 103 / \mu \mathrm{L}$ vs $7.1 \pm 2.1 \times 103 / \mu \mathrm{L} ; \mathrm{p}=0.044)$. There were 3 patients with positive anti-HCV. None of them were with positive HBcAb and HBsAb. Also, HCV-RNA was found negative for each individual as well. Variables those found significantly associated with $\mathrm{HBCAb}$ were assessed in linear regression analysis (variables: age, HBsAb, WBC and $D M)$. HBCAb was found independently associated with age (t: 3.139; $p=0.002$ ), HBsAb (t: 3.998; $p<0.001$ ), WBC $(t: 2.166 ; p=0.031)$ and DM existence (t: 2.749; $p=0.006)$.

\section{Discussion}

The purpose of the study was to draw attention to the overlooked high rates of HBCAb positivity in hemodialysis patients consisting of immune-compromised individuals. In our cohort, we found no HBV-DNA and therefore
$\mathrm{OBI}$ cases in patients with positive HBcAb. On the other hand, although it was not clearly known if patients were exposed to HBV before or after the initiation of dialysis, we found high rates of positive HBCAb. Despite the low number of patients, 59 of 241 (24\%) patients were with positive $H B C A b, 2$ of them $(0.8 \%)$ were with isolated positive $H B C A b$.

In our study, patients with positive HBcAb were older compared to patients with negative HBcAb. This may be due to the higher chance of being exposed to HBV. There is a strong association of DM with age (11). This may be the reason of the statistically significant difference between groups in terms of DM in our cohort.

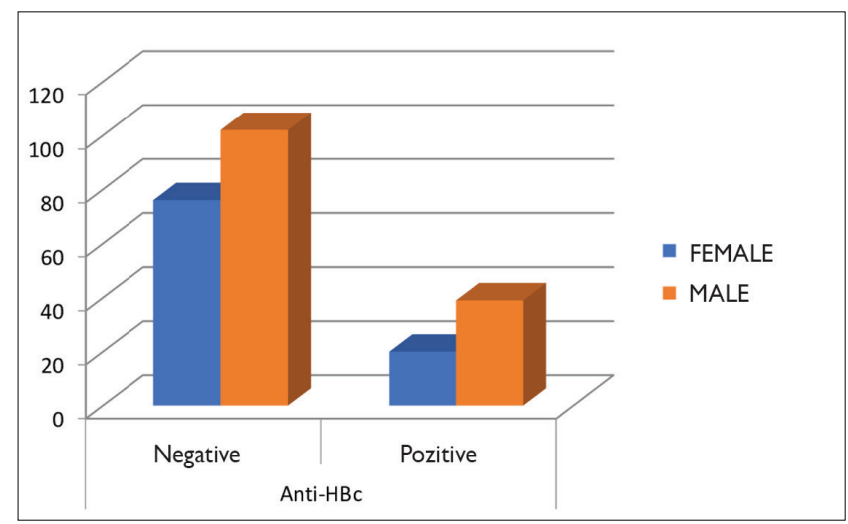

Figure 1. Distribution of patients in group 1 and group 2 in terms of gender

Anti-HBc: Anti-hepatitis B core

\begin{tabular}{|c|c|c|c|}
\hline & HBcAb positive $(n=59)$ & HBcAb negative $(n=178)$ & $p$ \\
\hline Age (years), mean $\pm S D$ & $64 \pm 11$ & $60 \pm 15$ & $0.018^{*}$ \\
\hline Gender F/M & $34 / 66$ & $43 / 57$ & 0.230 \\
\hline AST (U/L) [Median (IQR)] & $10(8)$ & $13(8)$ & $0.020 * *$ \\
\hline ALT (U/L) [Median (IQR)] & $8(7)$ & $10(7)$ & $0.046 * *$ \\
\hline $\mathrm{HbA} 1 \mathrm{c}(\%)$, mean $\pm \mathrm{SD}$ & $8.5 \pm 1.3$ & $8 \pm 1.2$ & 0.151 \\
\hline $\mathrm{Kt} / \mathrm{V}$ (min: 1.2$),$ mean $\pm \mathrm{SD}$ & $1.5 \pm 0.3$ & $1.6 \pm 0.4$ & 0.104 \\
\hline URR (\%) $(\min 65 \%)$, mean \pm SD & $71 \pm 7$ & $72 \pm 8$ & 0.490 \\
\hline HBsAb Titer (m IU/mL) [Median (IQR)] & $196.6(469.1)$ & $136.2(425.6)$ & 0.111 \\
\hline Transfusion history $n,(\%)$ & $81 \%$ & $85 \%$ & 0.528 \\
\hline DM n, (\%) & $32 \%$ & $19 \%$ & $0.036^{* * *}$ \\
\hline Albumin $(\mathrm{g} / \mathrm{dL})$, mean $\pm \mathrm{SD}$ & $3.8 \pm 0.5$ & $4.1 \pm 2.9$ & 0.395 \\
\hline Hemoglobin $(\mathrm{g} / \mathrm{dL})$, mean $\pm \mathrm{SD}$ & $11 \pm 2$ & $11 \pm 1.8$ & 0.690 \\
\hline Hematocrit (\%), mean \pm SD & $33 \pm 6$ & $33 \pm 5$ & 0.984 \\
\hline Platelet $(x 103 / \mu \mathrm{L})$, mean \pm SD & $227 \pm 71$ & $222 \pm 72$ & 0.644 \\
\hline WBC $(\times 103 / \mu \mathrm{L})$, mean \pm SD & $7.7 \pm 2.5$ & $7.1 \pm 2.1$ & $0.044^{*}$ \\
\hline
\end{tabular}


The immunosuppressive nature of chronic kidney disease (CKD) is due to the combined effects of many factors including chronic inflammation, uremia and dysfunction of both adaptive and innate immune system (12).

CKD results in a state of immunosuppression that is likely multifactorial due to a combination innate and adaptive immune system dysfunction, chronic inflammation, endothelial cell dysfunction and uremia (12). Since hemodialysis patients are immune suppressed patients, they are in the high-risk group for $\mathrm{OBI}$ reactivation. Although we detected no positive HBV-DNA, these high rates of positive $\mathrm{HBCAb}$ carry a high risk of HBV reactivation and possible adverse clinical outcomes.

Conventional serologic testing used in most dialysis centers is not able to identify the $\mathrm{OBI}$ (13). HBcAb was shown to be a useful marker for the detection of $O B I$ in the literature (14). In a study, 996 healthy blood donors were evaluated and $2.4 \%$ revealed isolated positive $\mathrm{HBcAb}$. Two of 23 patients (8.6\%) were with positive HBV-DNA (15). Tarif et al. (16) evaluated the prevalence of isolated positive $\mathrm{HBCAb}$ status in non-vaccinated CKD patients in terms of previous exposure and found $51 \%$ among $\mathrm{HBs} A g$ negative CKD patients. In our study, we found 2 (0.8\%) patients with isolated positive $\mathrm{HBcAb}$, who were non-vaccinated. The reason why the rates of isolated positive $H B C A b$ in our cohort were found relatively low might be due to the tight vaccination program of hemodialysis patients.

Studies in the literature about the OBI prevalence among hemodialysis patient era revealed low level of OBI. In a study, Aghakhani et al. (17) detected OBI in $50 \%$ of patients with positive anti-HBcAb. On the other hand, in agreement with our study, neither Fabrizi et al. (18) nor Jardim et al. (19) found positive HBV-DNA in their hemodialysis patients with positive HBcAb. Ramezani et al. (20) found $1 \%$ of patients on hemodialysis had $O B I$ with positive HBV-DNA. The clinical importance of $\mathrm{OBI}$ depends on its' possible consequences associated with immune status. In the literature, although HBsAb was positive, both HBV transmission from $\mathrm{OBI}$ cases and HBV reactivation under immunosuppressive therapy in patients with $\mathrm{OBI}$ were shown in the studies (21). This reflects the importance of $\mathrm{HBCAb}$ screening even in patients with positive $\mathrm{HBsAb}$. Also, dialysis patients may receive a kidney transplant at a later time in their course. Having an HBV infection may affect several aspects on their kidney transplant care in which immune suppressive medications are used to avoid rejection. Therefore, positive $H B c A b$, either isolated or with positive $\mathrm{HBsAb}$, should be taken into account in immune-compromised patients such as dialysis patients and the possibility of $\mathrm{OBI}$ should be excluded be checking HBV-DNA.
In fact, patients with positive isolated HBcAb those admitted to the hospital with immediate need of dialysis, should be dialyzed on HBV positive machines in order to avoid exposing HBsAg negative patients to potential infection. Hypo-transaminase is a well-recognized feature in dialysis patients with or without liver disease. The normal range of transaminases should be adjusted downwards; otherwise, the incidence or severity of clinical liver disease might be underestimated. In this regard, levels of 24 and $17 \mathrm{IU} / \mathrm{L}$ have been recommended as the upper limits of normal AST and ALT levels, respectively, in dialysis patients (10). In our study, mean AST and ALT levels in HBCAb positive and HBCAb negative patients were 10 (8) $\mathrm{U} / \mathrm{L}$ vs 13 (8) $U / L$ and 8 (7) $U / L$ vs 10 (7) $U / L$, respectively.

The $\mathrm{OBI}$ prevalence was found to be increased in patients with positive HCV probably due to the inhibition of HBV replication via interference of HCV in the hepatocyte $(22,23)$.

On the contrary, in the literature, there are several studies those found no association between HCV and $\mathrm{OBI}$ (24-26). In our study, there were 3 patients with $\mathrm{HCV}$. None of them were with either positive HBcAb or HBV DNA. This might be due to the insufficient number of patients with HCV in our cohort. Elevation of markers associated with liver damage may not be seen in dialysis patients due to suppression of inflammatory reactions due to chronic uremia (27). For this reason, to rule out OBI, HBV-DNA testing is crucial in dialysis patients (28). This can be considered as another justification for the necessity of administering HBV-DNA in the routine evaluation of hemodialysis patients with positive $H B c A b$.

In the literature, in vast majority of $\mathrm{OBI}$ cases serum viral load was reported about $20 \mathrm{IU} / \mathrm{mL}$ or undetectable (29). In our study, we found no viral load in patients with positive HBcAb. This might be due to fluctuation of viral load or relatively small number of patients.

Using erythropoiesis-stimulating agents in dialysis patients resulted in diminished need for transfusion. In addition, tight vaccination programs and screening blood products for viral markers contributed to decreasing of HBV infection in dialysis. In our study, we evaluated the transfusion rates and found no a significant difference between groups. Between groups, there was significant difference in terms of HBsAb titers. This may be due to the contribution of natural immunity after exposure to HBV to vaccination-associated immunity in patients with positive $\mathrm{HBcAb}$. Also, we evaluated the mean time after the last vaccination dose and its' correlation with antibody titers and found no statistically significant difference between patients with positive HBsAb. The mean antibody levels were above the protective levels, which is accepted to be above $100 \mathrm{IU} / \mathrm{L}$, at both groups. This may be related to 
tight vaccination program and close follow-up procedures in our cohort.

\section{Study Limitations}

Number of patients was relatively small in our cohort. Also, we could not rule out seronegative OBI because not of not checking HBV-DNA in patients with HBcAb and $\mathrm{HBsAb}$ are both negative.

\section{Conclusion}

Due to the risk of viral reactivation, the importance of HBCAb should not be underestimated particularly in patients with immune suppression such as dialysis patients. HBsAg and HBcAb must be checked together. In addition, HBV-DNA testing should be performed in patients with positive HBcAb.

\section{Authorship Contributions}

Concept: I.B., S.T., Design: I.B., Data Collection or Processing: I.B., Analysis or Interpretation: I.B., S.T., Literature Search: I.B., S.T., Writing: I.B.

Conflict of Interest: The authors declared no potential conflicts of interest with respect to the research, authorship, and/or publication of this article.

Financial Disclosure: The authors received no financial support for the research, authorship, and/or publication of this article.

\section{References}

1. Kataruka M, Gupta S, Ramchandran R, Singh M, Dhiman RK, Lal Gupta K. Incidence and Risk Factors for Hepatitis C Virus and Hepatitis B Virus Seroconversion in End-Stage Renal Failure Patients on Maintenance Hemodialysis. J Clin Exp Hepatol 2020;10:316-21.

2. Asif M, Ahmed R, Ahmed T, Uddin Z, Zahid M, Ullah I. Frequency Of Hepatitis-B And C In Patients On Haemodialysis For End Stage Renal Disease In Tertiary Care Hospitals: A Multicentre Study. J Ayub Med Coll Abbottabad 2020;32:3425.

3. Finelli L, Miller JT, Tokars JI, Alter MJ, Arduino MJ. National surveillance of dialysis-associated diseases in the United States, 2002. Semin Dial 2005;18:52-61.

4. Soi V, Soman S. Preventing Hepatitis B in the Dialysis Unit. Adv Chronic Kidney Dis 2019;26:179-84.

5. Wong GL, Wong VW, Yuen BW, et al. Risk of hepatitis B surface antigen seroreversion after corticosteroid treatment in patients with previous hepatitis B virus exposure. J Hepatol 2020;72:57-66.

6. Makvandi M. Update on occult hepatitis B virus infection. World J Gastroenterol 2016;22:8720-34.

7. Cendrero RM RC, Castellano BC, Hidalgo-Barquero MVM, et al. When can it be useful to look for occult HBV in hemodialysis patients? Nefrologia 2020;40:115-212.
8. Lim JK, Nguyen MH, Kim WR, Gish R, Perumalswami , Jacobson IM. Prevalence of Chronic Hepatitis B Virus Infection in the United States. Am J Gastroenterol 2020;115:1429-38.

9. Mak LY, Wong DK, Pollicino T, Raimondo G, Hollinger FB, Yuen MF. Occult hepatitis B infection and hepatocellular carcinoma: Epidemiology, virology, hepatocarcinogenesis and clinical significance. J Hepatol 2020;73:952-64.

10. Ravel V, Streja E, Molnar MZ, et al. Association of aspartate aminotransferase with mortality in hemodialysis patients. Nephrol Dial Transplant 2016;31:814-22.

11. Selvin E, Parrinello CM. Age-related differences in glycaemic control in diabetes. Diabetologia 2013;56:2549-51.

12. Ishigami J, Matsushita K. Clinical epidemiology of infectious disease among patients with chronic kidney disease. Clin Exp Nephrol 2019;23:437-7.

13. Winston A, Wurcel AG, Gordon C, Goyal N. Viral hepatitis in patients on hemodialysis. Semin Dial 2020;33:254-62.

14. Esposito A, Sabia C, lannone C, Nicoletti GF, Sommese L, Napoli C. Occult Hepatitis Infection in Transfusion Medicine: Screening Policy and Assessment of Current Use of Anti-HBC Testing. Transfus Med Hemother 2017;44:263-72.

15. Bhatti FA, Ullah Z, Salamat N, Ayub M, Ghani E. Anti-hepatits $B$ core antigen testing, viral markers, and occult hepatitis $B$ virus infection in Pakistani blood donors: implications for transfusion practice. Transfusion 2007;47:74-9.

16. Tarif N, Riaz MM, Sabir O, Akhter R, Rafique K, Rizvi N. Prevalence of Hepatitis $B$ core antibodies with negative Hepatitis B surface antigen in dialysis and chronic kidney disease patients. Saudi J Kidney Dis Transpl 2017;28:869-73.

17. Aghakhani A, Banifazl M, Kalantar E, et al. Occult hepatitis $B$ virus infection in hemodialysis patients with isolated hepatitis B core antibody: a multicenter study. Ther Apher Dial 2010;14:349-53.

18. Fabrizi F, Messa PG, Lunghi G, et al. Occult hepatitis B virus infection in dialysis patients: a multicentre survey. Aliment Pharmacol Ther 2005;21:1341-7.

19. Jardim RN, Gonçales NS, Pereira JS, Fais VC, Gonçales Junior FL. Occult hepatitis B virus infection in immunocompromised patients. Braz J Infect Dis 2008;12:300-5.

20. Ramezani A, Aghasadeghi MR, Ahmadi F, et al. Isolated antihbc and occult HBV infection in dialysis patients. Nephrourol Mon 2014;7:22674.

21. Levicnik-Stezinar S, Rahne-Potokar U, Candotti D, Lelie N, Allain JP. Anti-HBs positive occult hepatitis B virus carrier blood infectious in two transfusion recipients. J Hepatol 2008;48:1022-5.

22. Murai $K$, Hikita $H$, Kai $Y$, et al. Hepatitis $C$ virus infection suppresses hepatitis B virus replication via the RIG-l-like helicase pathway. Sci Rep 2020;10:941. 
23. Muto J, Sugiyama M, Shirabe $K$, et al. Frequency and Characteristics of Occult Hepatitis B Infection Among Hepatocellular Carcinoma Patients in Japan. Ann Hepatol 2018;17:596-603.

24. El Makarem MA, Hamid MA, Aleem AA, et al. Prevalence of occult hepatitis $B$ virus infection in hemodialysis patients from Egypt with or without hepatitis $C$ virus infection. Hepat Mon 2012;12:253-8.

25. Ismail H, Soliman M, Nahed Ismail N. Occult hepatitis B virus infection in Egyptian hemodialysis patients with or without hepatitis C virus infection. Pathol Lab Med Int 2010;2010:11320.

26. Zaki MES, Rafaat D, Eliwa A, Abdelsalam M. Occult hepatitis B among patients under hemodialysis at Mansoura University
Hospitals: Prevalence and risk factors. J Virol Antivir Res 2014;3:1-6.

27. Vanholder R, Pletinck A, Schepers E, Glorieux G. Biochemical and Clinical Impact of Organic Uremic Retention Solutes: A Comprehensive Update. Toxins (Basel) 2018;10:33.

28. Tang Y, Liu X, Lu X, He Q, Li G, Zou Y. Occult Hepatitis B Virus Infection in Maintenance Hemodialysis Patients: Prevalence and Mutations in "a" Determinant. Int J Med Sci 2020;17:2299-305.

29. Malagnino V, Fofana DB, Lacombe K, Gozlan J. Occult Hepatitis B Virus Infection: An Old Entity With Novel Clinical Involvements. Open Forum Infect Dis 2018;5:227. 